\title{
Perception of the traffic safety level provided in elementary school areas
}

\author{
S. Basbas ${ }^{1}$, A. Kokkalis ${ }^{2}$ \& C. Konstantinidou ${ }^{1}$ \\ ${ }^{\text {I}}$ Aristotle University of Thessaloniki, Greece \\ ${ }^{2}$ Democritus University of Thrace, Greece
}

\begin{abstract}
The need to provide a safer environment for vulnerable road users, such as pedestrians and cyclists, is inevitable. This need is more important in the case of students of elementary schools due to the fact that they are not in the position to easily realize the danger of the road traffic and thus take the necessary precautionary measures. In the framework of this paper the results of a research concerning the perceived traffic safety level provided in elementary school areas are presented. These elementary school students participated in questionnaire-based surveys in various Municipalities in Greece. The reasons for which students feel unsafe, their participation in traffic education events and the transport modes used for their trips to and from schools are examined and presented in this paper.
\end{abstract}

Keywords: traffic safety, travel behaviour, vulnerable road users, elementary school students.

\section{Introduction}

The domination of private vehicles is a very common phenomenon in most urban areas all over the world. Drivers often ignore vulnerable road users and especially pedestrians. Furthermore, the absence of adequate or well designed infrastructure for pedestrians makes the walking environment quite unfriendly for them. Research results have shown that people are ready to walk more than they used to (increase of walking distance at a percentage of $70 \%$ ) if an improved public space is provided (Tsourlakis [1]).

It is important to design and implement safety measures near school areas, which are the places that attract the majority of children on a daily basis, due to 
the fact that children are not in a position to realize and assess the danger of traffic.

This paper attempts to investigate the perception of the level of traffic safety in elementary school areas in various Municipalities in Greece as revealed from questionnaire-based surveys.

\section{Students of elementary schools}

It is well known that children belong to the group of vulnerable road users. "Vulnerable road users" is a term commonly used to describe those groups who are likely to suffer when in conflict with cars, buses and other large vehicles (Apostolidis et. al. [2]).

One of the most problematic characteristics of children who walk is that their movements are less predictable than those of adults. Children walk simultaneously with vehicular traffic on the street or cross the street without looking for the oncoming traffic.

Children also cannot estimate the speed of vehicles and as a result accidents are a usual phenomenon near places which attract children, e.g. school areas. Children, especially five to nine years old, do not know the Highway Code and how to react in traffic situations. This is the reason why special attention needs to be paid to this specific group of vulnerable road users.

An indicative list of special considerations for the trip needs of children in the age of five to nine years old is presented below (Washington State Department of Transportation [3]):

- Children are shorter than adults; typical eye height is 1 meter ( 3 feet) above ground; their field of vision is different.

- Children have one-third narrower side vision than adults and are not able enough to determine the direction of sounds.

- Children have trouble with speeds and distances of moving cars.

- Children are sometimes too small to be seen by fast moving or inattentive drivers.

- The movements of children are less predictable than adults.

- Children have shorter attention spans and may grow impatient at crossings.

- Children have less experience as pedestrians and may not be fully aware of dangerous conditions.

\section{School areas and road safety}

A school area must be characterized by the provision of a safe and comfortable trip environment from the child's home to school and backwards. According to the Institute of Transportation Engineers (ITE) manual (Design and Safety of Pedestrian Facilities [4]) "the majority of drivers do not typically reduce their speed in school zones unless they perceive a potential risk, such as the presence of police or crossing guards, or clearly visible children". At this point it should be noted that despite the speed management measures which are implemented near schools in the Municipalities of Thessaloniki, many drivers violate the 
respective speed limits (Themelis and Dumas [5]). A pedestrian-friendly school environment is the one that promotes, first of all, safe walking.

\subsection{School site}

A walkable school environment is influenced by school site and school site design. Thus, whenever possible, schools should be located, Dover et al. [6]: on a street which is connected with other streets, with a distance of one quarter mile from a transit stop, near mix land use area with distance one-quarter mile of it, in an area which has good visibility "eyes on the street" for 24 hours a day, in a neighbourhood with a complete sidewalk network, in an area with trees next to the roads, near traffic calming areas, "in a neighbourhood with clearly defined or guarded crosswalks" and near streets that is easy for pedestrians to cross the road with safe and comfort.

An effort has been made in Greece to have the entrance/exit of schools on streets which are either pedestrian streets or local streets with low traffic volumes. The main problem is that proper locations cannot be easily found for the construction of new schools due to the fact that no empty space is available in most of the cities in the country.

\subsection{Traffic control and crossing treatments near school areas}

Traffic calming can be an effective means to create a safer and more comfortable environment for children's daily walking to and from school. There are several types of crossing treatments and traffic control devices that may be appropriate in school zones and along school walk routes under varying conditions. Crossing treatments are usually necessary at locations where adequate "gaps" are not available in vehicular flow in order to allow children to safely cross the road.

The potential types of traffic control and crossing treatments that may be implemented near schools include: raised crossings, refuge islands, traffic signals with pedestrian actuators, humps, increase of green signal time, pavement widening, markings, school policeman (Skyrgiannis [7]), good visibility for children, signing and marking (Basbas [8]). It should be noted that there were no traffic accidents near school areas, where there were school policeman, according to a research which was carried out in Germany during the period 1976-1994.

\section{Children and traffic accidents}

Children and young people in general are 100 times more likely to be killed as road users compared to other road users (Prezza et. al. [9]). According to recent forecasts (Tsourlakis [1]), road accidents will be the third cause of deaths in the year 2020. Survey results indicate that young people who live near areas characterized by low traffic volumes (i.e. suburban areas) "see" or experience a somewhat nicer, more pleasant, more supportive and more likeable local environment than those who live in areas characterized by high traffic volumes. 
The position of children as a vulnerable road user is justified by the percentage of road accidents which is associated to them. According to the results of a survey which was carried out in France, it was considered that the age group with the biggest involvement in road accidents was that of children aged from six to eight (Cambon et. al. [10]).

Preston [11] as well as the Department for Transport in UK [12] mention that the typical land use characteristics of areas associated with a high child accident rate include: "lack of open space (gardens and play areas), street frontage access, parking areas, high level of on-street car parking, long and straight streets and high volume of traffic".

According to Petch and Henson [13], the frequency of accidents was strongly correlated to traffic volume and vehicle speed. In addition, "the $90 \%$ of the child pedestrian accidents occurred on through traffic roads". The results of a survey investigating the relationship between quality of life and child traffic fatalities show that "with the exception of the bicycle fatalities, traffic fatalities among children tend to decline with increasing quality of life" (Darcin and Darcin [14]).

According to the child casualty statistics, two children in a class of 30 are expected to be killed or injured in a road accident before their 16th birthday (Dept. of Environment, Transport and Regions, UK [15]).

\section{Safety in the Greek road network}

Road accidents are one of the main causes of deaths in Greece every year, especially for children and elderly people. The respective socioeconomic cost is huge due to the high number of road accidents that occur. Every year more than 1,600 people die and more than 20,000 get injured (N.T.U.A. [16]). According to Spathopoulos, [17], a sensitive group of pedestrian's injuries in road accidents refer to children and especially to those who belong in the ages of 5 to 10 years old.

One of the main reasons of the involvement of pedestrians and especially of children in road accidents is the relatively poor infrastructure (i.e. pedestrian crossings, sidewalks etc) and the non compliant drivers' behaviour (i.e. high speed, illegal parking, aggressive driving etc). An attempt is made in the following sections to associate students' perception about safety level provided near elementary school areas in various Municipalities in Greece.

\section{Questionnaire-based surveys in elementary schools}

In order to better understand and assess the perception of the level of traffic safety provided in elementary school areas by their students, questionnaire-based surveys were carried out in five elementary schools in two Municipalities of Thessaloniki (Municipalities of Thessaloniki and Kalamaria) and four elementary schools in the Municipality of Larissa. These surveys were carried out in the framework of the research activities of the Faculty of Rural \& Surveying Engineering, Aristotle University of Thessaloniki. It must be 
mentioned at this point that traffic calming measures implemented in the near area of the elementary schools under study are considered to be quite satisfactory.

\subsection{Questionnaire-based survey in the Municipality of Kalamaria}

The Municipality of Kalamaria is part of the Thessaloniki Greater Area (TGA), Northern Greece, and has a population of 87,312 residents (is the second biggest Municipality in TGA). It is characterized by high population density and high traffic volumes. The research in the Municipality of Kalamaria included four elementary schools (Themelis and Dumas [5]).

A questionnaire about traffic safety near schools was given to the students of the sixth grade of the elementary schools. According to the research results (65 questionnaires), $17 \%$ of the respondents feel very unsafe during their arrival and departure to/from school. A percentage of $12 \%$ of the students feel unsafe, $46 \%$ feel little unsafe and $25 \%$ of students feel safe during their trips near to school areas (see Figure 1).

The main reasons that students feel very unsafe and unsafe during their arrival and departure to/from school are: $38 \%$ due to high vehicle speed, $26 \%$ due to high volume of traffic, $2 \%$ due to inadequate pavements, $8 \%$ due to the absence of pedestrian crossings, $13 \%$ due to parked cars, $10 \%$ due to inadequate lighting and $3 \%$ to other reasons (see Figure 2). It is clear enough that students mainly feel unsafe because of the high vehicle speed.

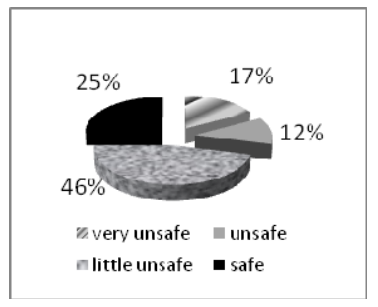

Figure 1: $\quad$ Feeling about traffic safety in the elementary school areas.

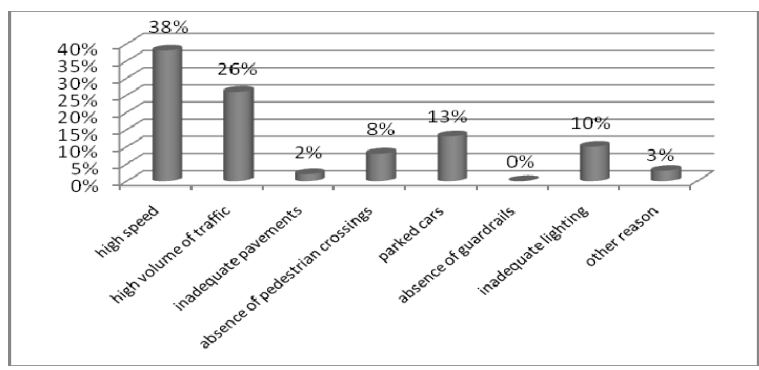

Figure 2: $\quad$ Reasons for which students feel unsafe. 
In addition, the students were asked to state if they had ever participated in a traffic education event (such events are usually organized by the school administration in conjunction with the police). It was found that $51 \%$ of students had participated in a traffic education.

The feeling about traffic safety concerning students who had participated in a traffic education event is presented in Figure 3. As it can be seen in this Figure, $12 \%$ feel very unsafe near school areas, $15 \%$ feel unsafe, $43 \%$ feel little unsafe and $30 \%$ feel safe during their trips to and from schools.

In terms of the transport modes used for the trips near school areas, $12 \%$ of students go to school by private car, as car passengers, 3\% use their bicycle, $36 \%$ go to school on foot (alone), 3\% go to school on foot accompanied by elder people and $46 \%$ go to school on foot with other classmates.

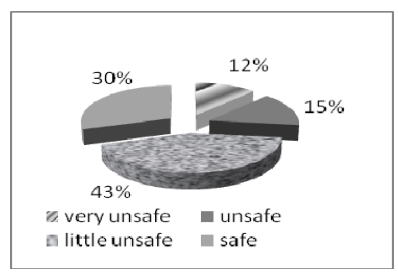

Figure 3: $\quad$ Feeling about traffic safety for students who have participated in a traffic education event.

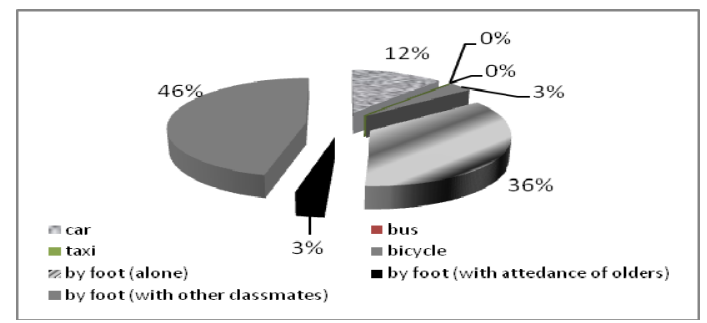

Figure 4: $\quad$ Transport modes used to and from schools.

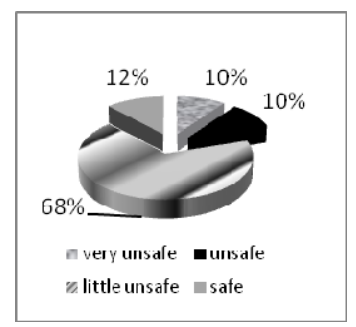

Figure 5: Feeling of traffic safety for students who walk with other classmates. 
As it is noticed, the $85 \%$ of students walk in order to arrive at school or return home. Figure 4 presents the transport modes used by the students for their daily trips to and from schools. In addition, it should be noticed that as far as students trips on their way to and from school with other classmates are concerned, $10 \%$ feel very unsafe, $10 \%$ feel unsafe, $68 \%$ feel little unsafe and $12 \%$ feel safe during their trips in school area (Figure 5).

The students who walk to school with other classmates feel very unsafe and unsafe for the following reasons: high speed of vehicles $(41 \%)$, high volume of traffic $(21 \%)$, inadequate pavements $(4 \%)$, absence of pedestrian crossings $(3 \%)$, parked cars $(14 \%)$, inadequate lighting (14\%) and other reasons $(3 \%)$. As expected the main cause of students' fear is the high vehicle speed (Figure 6).

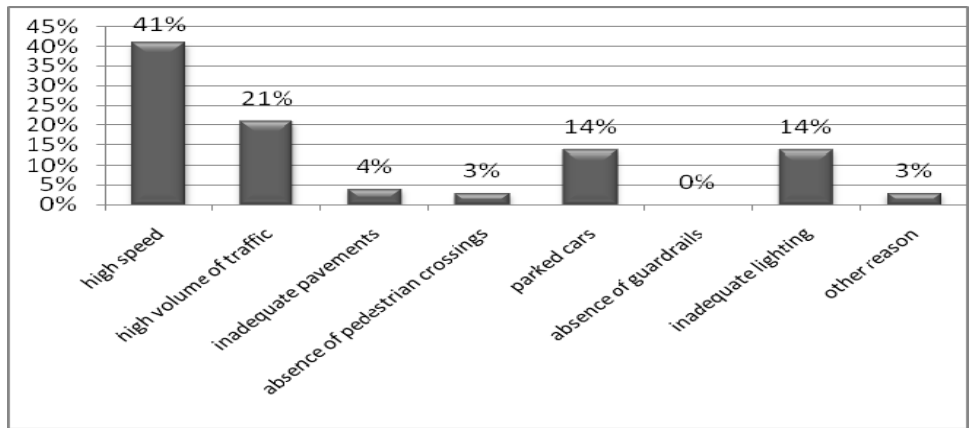

Figure 6: Reasons for feeling unsafe (students who walk to school with other classmates).

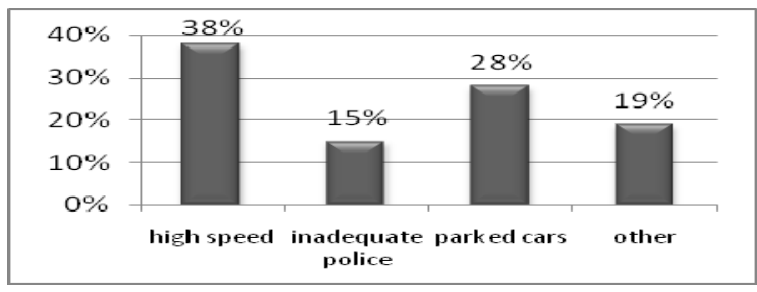

Figure 7: $\quad$ Reasons for which students feel unsafe.

\subsection{Questionnaire-based survey in the Municipality of Thessaloniki}

The population of the municipality of Thessaloniki (the biggest municipality in TGA) includes 385,406 residents. A questionnaire-based survey (73 questionnaires) was carried out in an elementary school in the eastern part of the Municipality (Visba and Stamos [18]).

The majority of students $(59 \%)$ feel unsafe when crossing the road. It is interesting to notice that $89 \%$ of the students believe that school areas are inadequate for their trips on foot while only $11 \%$ are satisfied from the walking environment. The main reason that students feel unsafe is high vehicle speed $(38 \%)$, as shown in Figure 7. 


\subsection{Questionnaire-based survey in the Municipality of Larissa}

Larissa is one of the biggest Municipalities in Greece and it is part of the Prefecture of Thessaly, Central Greece. Its population is 124,394 according to the results of the 2001 census. Larissa is characterized by an extensive network of pedestrian streets, especially in its centre. A questionnaire-based research in four elementary school areas was carried out in order to assess the traffic safety/accessibility difficulties of students during their daily trips from and to schools (Giatas and Pampouridis [19]). The questionnaire was addressed to the students of the sixth grade of the elementary schools (160 questionnaires). Results have shown that $9 \%$ of the students feel very unsafe during their arrival and departure from school, 11\% feel unsafe, 37\% little unsafe and $43 \%$ feel safe near school areas (see Figure 8).

It is interesting to notice that $87 \%$ of the students participated in a traffic education event (compared to $51 \%$ in the Municipality of Kalamaria). It should be mentioned that, $12 \%$ of students who participated in a traffic education event feel very unsafe near school areas, $8 \%$ feel unsafe, 38\% feel little unsafe and $42 \%$ feel safe during their arrival and departure to school as it is shown in Figure 9. As it can be seen, $58 \%$ of students who participated in a traffic education event feel some kind of concern during their trips to and from school.

In terms of the transport modes used for the trips to and from schools, $11 \%$ of students in Larissa go to school by private car, $1 \%$ use their bicycles, $1 \%$ use the PT bus, 32\% go to school on foot (alone), 11\% go to school on foot accompanied by elder people and $44 \%$ go to school on foot with other classmates (Figure 10).

At this point it should be mentioned that $10 \%$ of students who walk alone to and from school feel very unsafe when move near school area on foot, $4 \%$ feel unsafe, $37 \%$ feel little unsafe and $49 \%$ feel safe. Thus, a percentage of $51 \%$ of students experience difficulties during their daily trips to and from school (Figure 11).

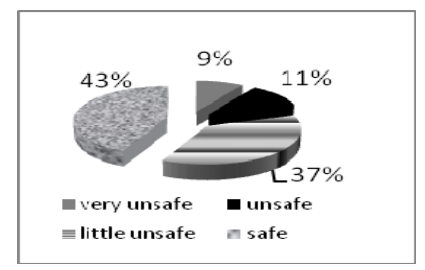

Figure 8: $\quad$ Feeling about traffic safety in the elementary school areas.

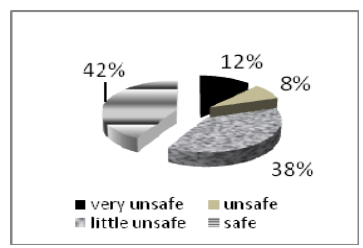

Figure 9: $\quad$ Feeling about traffic safety for students who have participated in a traffic education event. 


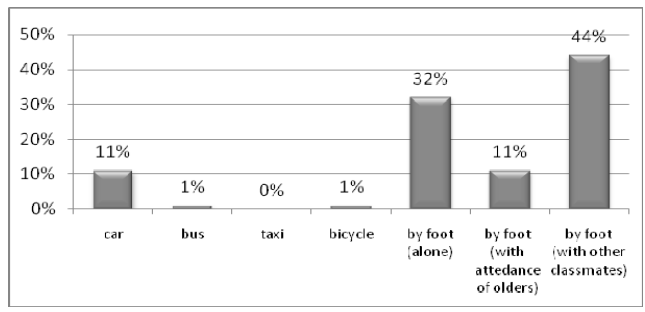

Figure 10: Transport modes used to and from schools.

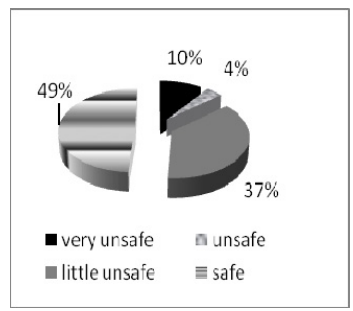

Figure 11: Feeling about traffic safety for students who walk alone to and from school.

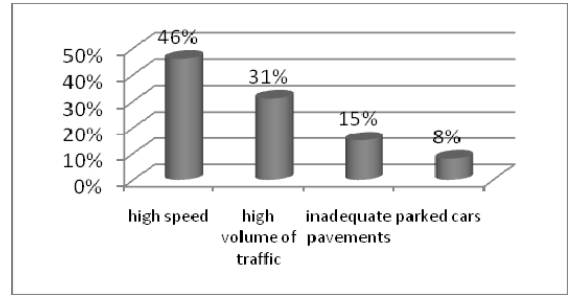

Figure 12: $\quad$ Reasons for feeling unsafe (students who walk alone).

The reasons for which students feel unsafe during their trip to school on foot are: high speed of vehicles $(46 \%)$, high volume of traffic $(31 \%)$, inadequate pavements $(15 \%)$ and parked cars $(8 \%)$ as shown in Figure 12.

\section{Conclusions}

The results presented in the previous sections are quite revealing about elementary school students, and their perceived needs, as far as traffic safety is concerned in three Greek Municipalities. The main findings for the Municipality of Kalamaria can be summarised as follows:

- With respect to traffic safety, $75 \%$ of students feel some kind of concern during their trips near school areas.

- Students state that high vehicle speed (38\%) and high traffic volumes $(26 \%)$ are the main reasons for feeling unsafe.

- $51 \%$ have participated in a traffic education event. As far as this specific group is concerned, $70 \%$ of them feel unsafe near school areas. 
- $\quad 85 \%$ of the students' trips to and from school are made on foot. In terms of the students who walk to school with other classmates, $88 \%$ of them experience difficulties (main reasons refer to high speed of vehicles (41\%) and high traffic volume $(21 \%))$.

With reference to the Municipality of Thessaloniki, 59\% of elementary school students feel unsafe during their trips to and from school. In addition, $89 \%$ of them stated that the school area is not characterised by comfort and attractiveness. The main reasons for feeling unsafe are high vehicle speed $(38 \%)$ and the existence of parked cars $(28 \%)$.

The main results concerning the Municipality of Larissa can be summarised as follows:

- With respect to traffic safety, $57 \%$ of students feel some kind of concern during their trips near school areas.

- Students who walk alone state that high speed of vehicles (46\%) and high traffic volumes $(31 \%)$ are the main reasons for feeling unsafe.

- $87 \%$ of the students have participated in a traffic education event, of which $58 \%$ feel unsafe near school area.

- In terms of the transport modes used for the trips to and from schools, $87 \%$ of students prefer to walk. $51 \%$ of the students who walk alone, experience difficulties during their trips to and from school.

In conclusion, students in the examined areas seem to exercise a non compliant environment when it comes to arrive or leave school. Based on the surveys carried out, the reasons claimed by students that cause concern to them are high vehicle speed and high traffic volumes. For these reasons, responsible authorities should try to provide a safer and friendlier walking environment for the students.

The efforts should also be focused in the provision of proper traffic education. In attaining this, different government levels need to be involved and promote "ways of legal walking" in the urban road networks and especially near school areas, with the aim to change students' behaviour. In addition, the promotion of safety actions such as general awareness campaigns, targeted campaigns to young children and students at schools, children games which motivate young students etc. should be identified (Papaioannou et al. [20]).

\section{References}

[1] Tsourlakis, K., Pedestrians and Road Safety in Greece, Proc. Of the $3^{\text {rd }}$ Pan-Hellenic Conf. on Road Safety, 2005.

[2] Apostolidis, C., Gaitazi, X. \& Kitsou, E., Evaluation of pedestrians characteristics in the centre of Thessaloniki, Diploma Thesis, Supervisor: Basbas, S., Faculty of Rural and Surveying Engineering, Aristotle University of Thessaloniki, 2008

[3] Washington State Department of Transportation, Pedestrian Facilities Guidebook, www.psrc.org

[4] ITE, Design and Safety of Pedestrians Facilities, http://safety.fhwa.dot.gov 
[5] Themelis, G. \& Dumas, A., Road safety level near school areas in Thessaloniki, Greece. Diploma Thesis, Supervisor: Basbas, S., Faculty of Rural and Surveying Engineering, Aristotle University of Thessaloniki, 2003.

[6] Dover, Kohl \& Partners, Chael, Cooper \& Associates P.A. Design Guidelines for Pedestrian-Friendly Neighbourhood Schools. www.raleighnc.gov

[7] Skyrgiannis, C. Road Safety in Schools Area, Facts and Suggestions for the Urban Area of Volos. Proc. of the $2^{\text {nd }}$ Pan-Hellenic Conf. on Road Safety, pp. 95-102, 1998.

[8] Basbas, S. Measures for the reduction of road accidents. Campaigns, One day Conf. on Road Safety, General Police Direction of Thessaloniki, Thessaloniki, pp. 1-9, 1999.

[9] Prezza, M., Romana, F.R, Alparone, Cristallo, C. \& and Luigi, S. Parental perception of social risk and of positive potentiality of outdoor autonomy for children: The development of two instruments, Journal of Environmental Psychology, 25(4), pp.437-453, 2005.

[10] Cambon de Lavalette B., Tursz A.\& Dechaud-Rayssiguier D. Les accidents de la circulation dans l'enfance, INRETS, Paris, 1989.

[11] Preston, B., Statistical Analysis of Child Pedestrian Accidents in Manchester and Salford, Manchester, UK, 1976.

[12] Department for Transport, Road accident involvement of children from ethnic minorities (No.19). www.dft.gov.uk

[13] Petch, R.O. \& Henson, R.R. Child road safety in the urban environment, Journal of Transport Geography, 8(3), pp. 197-211, 2000.

[14] Darcin, M. \& Darcin, E.S. Relationship between quality of life and child traffic fatalities, Accident Analysis \& Prevention, 39(4), pp. 826-832, 2007.

[15] Department of Environment, Transport and the Regions, 1998b. Department of Transport, Road Accidents in Great Britain: The Casualty Report, HMSO, London, UK, 1997.

[16] National Technical University of Athens, Road Safety Strategic Plan “2006-2010”, Scientific Coordinator: Kanellaidis, G., Athens, 2001.

[17] Spathopoulos K, 2005. Temporal evolution of accidents in Greece, M.Sc. Thesis, Supervisor: Papaioannou, P., Departments of Civil Engineering and Rural and Surveying Engineering, Aristotle University of Thessaloniki, 2005.

[18] Visba, C., \& Stamos, A., The impact of road safety to pedestrian trips in the road network, Diploma Thesis, Supervisor: Basbas, S., Faculty of Rural and Surveying Engineering, Aristotle University of Thessaloniki, 2007.

[19] Giatas, A. \& Pampouridis, A., Road safety level near school areas in Larissa, Greece, Diploma Thesis, Supervisor: Basbas, S., Faculty of Rural and Surveying Engineering, Aristotle University of Thessaloniki, 2006.

[20] Papaioannou, P., Basbas, S. \& Konstantinidou, C. Evaluation of policy measures and infrastructure provided for the needs of pedestrians in the city of Thessaloniki, Greece. Proc. of the $8^{\text {th }}$ annual Int. Conf. on walking and liveable communities, Walk 21, Toronto 2007-Putting Pedestrians First, pp.1-21, 2007. 